\title{
Dimethylamine as the key intermediate generated in situ from dimethylformamide (DMF) for the synthesis of thioamides
}

\author{
Weibing Liu* ${ }^{* 1}$, Cui Chen ${ }^{1}$ and Hailing Liu*2
}

\author{
Full Research Paper \\ Address: \\ ${ }^{1}$ College of Chemical Engineering, Guangdong University of \\ Petrochemical Technology, 2 Guandu Road, Maoming 525000, P. R. \\ China, Fax: +86-668-2923575; Tel: +86-668-2923956 and ${ }^{2}$ College \\ Analytical and Testing Centre, Beijing Normal University, No. 19, \\ Xinjiekouwai St., Haidian District, Beijing 100875, P. R. China; Tel: \\ $+86-15010928428$ \\ Email: \\ Weibing Liu* - liuhailing@bnu.edu.cn; \\ Hailing Liu* - liuhailing@bnu.edu.cn \\ * Corresponding author \\ Keywords: \\ aldehydes; dimethylformamide (DMF); elemental sulfur; ketones; \\ thioamides \\ Beilstein J. Org. Chem. 2015, 11, 1721-1726. \\ doi:10.3762/bjoc.11.187 \\ Received: 17 May 2015 \\ Accepted: 04 September 2015 \\ Published: 23 September 2015 \\ Associate Editor: B. Stoltz \\ (C) 2015 Liu et al; licensee Beilstein-Institut. \\ License and terms: see end of document.
}

\begin{abstract}
An improved and efficient method for the synthesis of thioamides is presented. For this transformation, dimethylamine as the key intermediate is generated in situ from dimethylformamide (DMF). All the tested substrates produced the desired products with excellent isolated yields.
\end{abstract}

\section{Introduction}

Thioamides, a well-known structural element of many sulfurcontaining molecules, synthetic agents [1,2], heterocycles, natural products and pharmaceuticals [3-8], have attracted considerable attention for their construction and use in organic synthesis $[9,10]$. Many compounds containing a thioamide motif are of medicinal significance and exhibit potent biological activities. These include for example opioid activity [11], immunosuppressive activity and DHODH inhibitory properties [12], activity against parasitic nematodes [13], and antituberculotic activity [14].
Consequently, a number of synthetic methods for the construction of this important unit have been established over the past decades [15-21]. However, some of these methods have limited applications, because of harsh conditions, low yields or the need of noble-metal catalysts. Therefore the development of novel and efficient methods for the construction of the thioamide motif is highly desirable. To avoid the disadvantages of the traditional methods, our group has developed an improved synthetic procedure to construct thioamides (Scheme 1). 


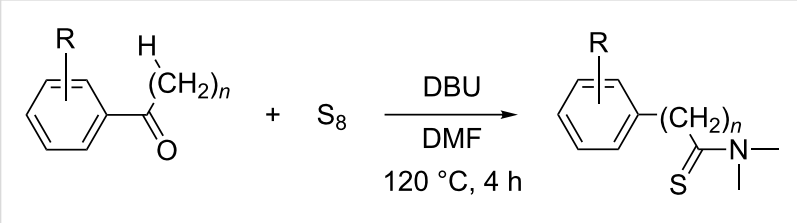

$n=0,1,2$

Scheme 1: Synthesis of thioamide derivatives.

\section{Results and Discussion}

Our initial efforts focused on the optimization of the reaction conditions by employing 4-methoxybenzaldehyde (1a) as a model reactant to interact with elemental sulfur and DMF (Table 1). The reaction is completed after $4 \mathrm{~h}$ at $120^{\circ} \mathrm{C}$, providing 4-methoxy- $N, N$-dimethylbenzothioamide (2a) with $64 \%$ yield by using sodium acetate (AcONa) as the base (Table 1 , entry 2). With regard to the catalytic activity of different bases (Table 1, entries 4-8), 1,8-diazabicyclo[5.4.0]undec-7-ene (DBU) showed the highest activity and afforded the desired product with $96 \%$ yield (Table 1, entry 7 ). It is worth mentioning that this conversion does not take place in the absence of a base (Table 1, entry 9). Lowering the temperature from $120{ }^{\circ} \mathrm{C}$ to $100{ }^{\circ} \mathrm{C}$ decreased the yield considerably (Table 1, entry 10). When the reaction was performed at room temperature no product was obtained at all (Table 1, entry 11).

Once the optimal conditions had been identified (Table 1, entry 7 ), next the scope of the reaction was investigated. Sixteen substrates including 12 substituted aldehydes and 4 ketones were screened and the results are presented in Table 2. As can be seen from the Table, all reactions proceeded smoothly and

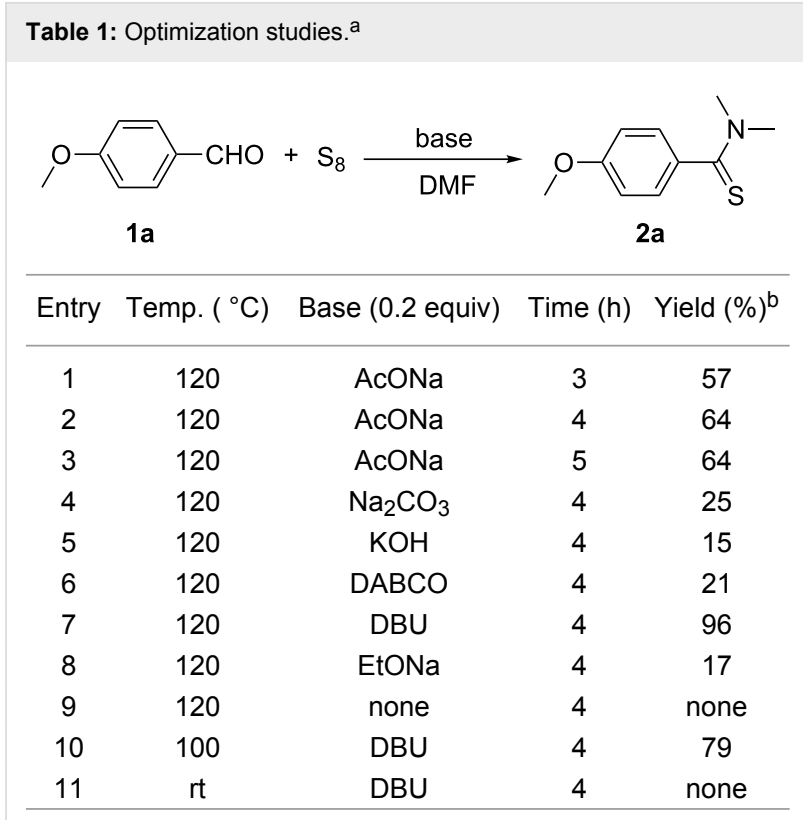

aReaction conditions: $1 \mathrm{a}(0.25 \mathrm{mmol}), \mathrm{S}_{8}$ (1.2 equiv, based on $1 / 8 \mathrm{~S}_{8}$ ), DMF $(2.0 \mathrm{~mL}){ }^{\text {b }} \mathrm{GC}$ yield.

gave the corresponding thioamides $\mathbf{2 a - p}$ exclusively in good to excellent isolated yields. It was also found that unsubstituted, mono-, di- and trisubstituted substrates regardless of the position $(o-, m-$, or $p-)$ and the electronic properties of the substituents (electron-donating or-withdrawing) on the benzene ring were all compatible with the standard conditions. For example, methoxy-, $o-, m$-, and $p$-methyl-, fluoro-, chloro-, or hydroxy-substituted aromatic aldehydes and ketones were all converted to their corresponding thioamides with excellent

Table 2: Scope of the reaction. ${ }^{\text {a }}$

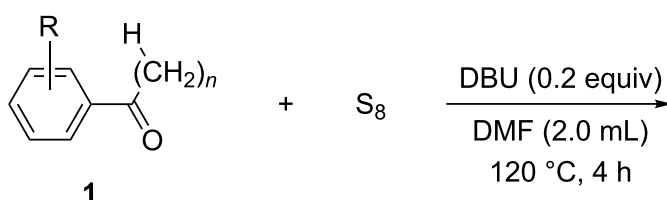

$n=0,1,2$

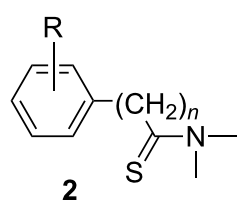

Entry Product 2a-p


Table 2: Scope of the reaction. ${ }^{\text {a }}$ (continued)<smiles>Cc1cccc(C=O)c1</smiles>
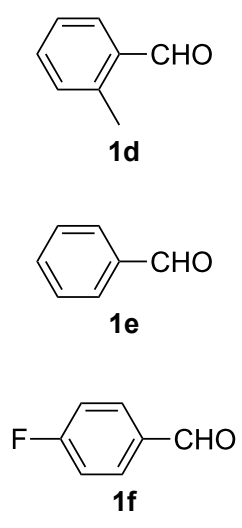

7

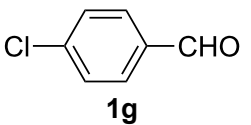

8

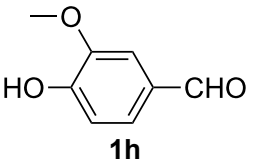

9

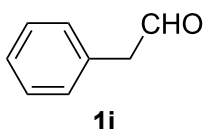

10

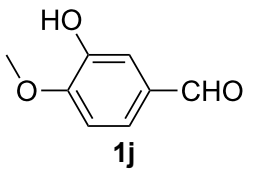

11

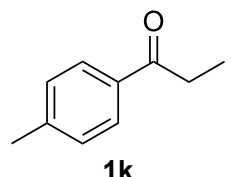

12

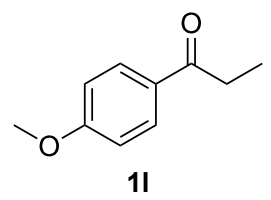

13

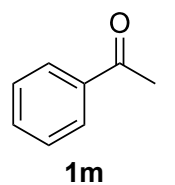

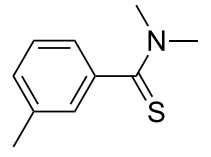

2c

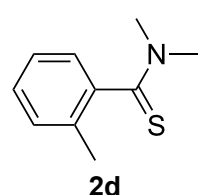

82

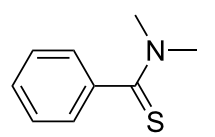

$2 e$

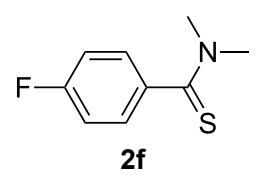

80

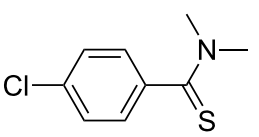

2g

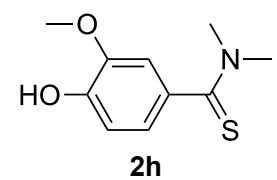

89

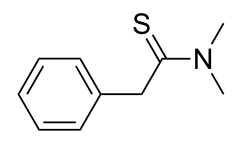

2i

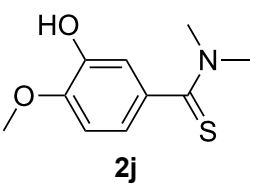

88<smiles>Cc1ccc(CCC(=S)N(C)C)cc1</smiles>

$2 k$<smiles>COc1ccc(CCC(=S)N(C)C)cc1</smiles><smiles>CN(C)C(=S)Cc1ccccc1</smiles>

77 
Table 2: Scope of the reaction. ${ }^{\text {a }}$ (continued)

14<smiles>CC(=O)c1ccc(C)cc1</smiles>

$1 n$

15<smiles>CCCC=O</smiles>

16

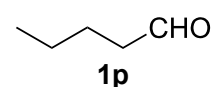<smiles>Cc1ccc(CC(=S)N(C)C)cc1</smiles>

$2 n$<smiles>CCCC(=S)N(C)C</smiles>

20<smiles>CCCCC(=S)N(C)C</smiles>

$2 p$

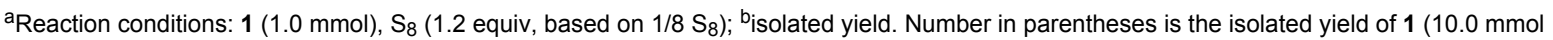
scale) after purification by column chromatography.

isolated yields. Finally, some aliphatic aldehydes such as phenylacetaldehyde (Table 2, entry 9), butyraldehyde (Table 2, entry 15) and pentanal (Table 2, entry 16) were subjected to the reaction. They were also found compatible with the standard conditions, and the corresponding products were isolated in moderate to good yields.

In order to expand the scope and to get insight into the reaction mechanism of this protocol, three control experiments were conducted (Scheme 2). In the first two experiments the reaction was performed with $N, N$-dimethylacetamide (DMA) and $N, N$ dimethylacrylamide instead of DMF under the standard conditions. In both cases no product formation was observed, suggesting that neither DMA nor $N, N$-dimethylacrylamide is able to promote the reaction. However, repeating the reaction in DMA in the presence of $N, N$-dimethylamine the desired product 2 a was obtained in $98 \%$ yield. These results are proving the involvement of dimethylamine in this transformation and that it is in situ generated from $\mathrm{N}, \mathrm{N}$-dimethylformamide under the reaction conditions.

Based on the above experiments and the existing literature [2224], a suggested mechanism is outlined in Scheme 3. The reaction starts with a base-induced cleavage of DMF to form the required dimethylamine according to the mechanism suggested by Van der Eycken, Hallberg and co-workers $[25,26]$. The subsequent step involves the classical Willgerodt-Kindler reaction as described by Amupitan and Darabi [27,28].<smiles>COc1ccc(C=O)cc1</smiles>

1a

$1 a$ $+\mathrm{S}_{8}+$<smiles>C=CC(=O)N(C)C</smiles><smiles>COc1ccc(C(=S)N(C)C)cc1</smiles>

2a

$2.0 \mathrm{~mL}$

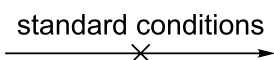

$2 a$

$2 a$

$98 \%$ 


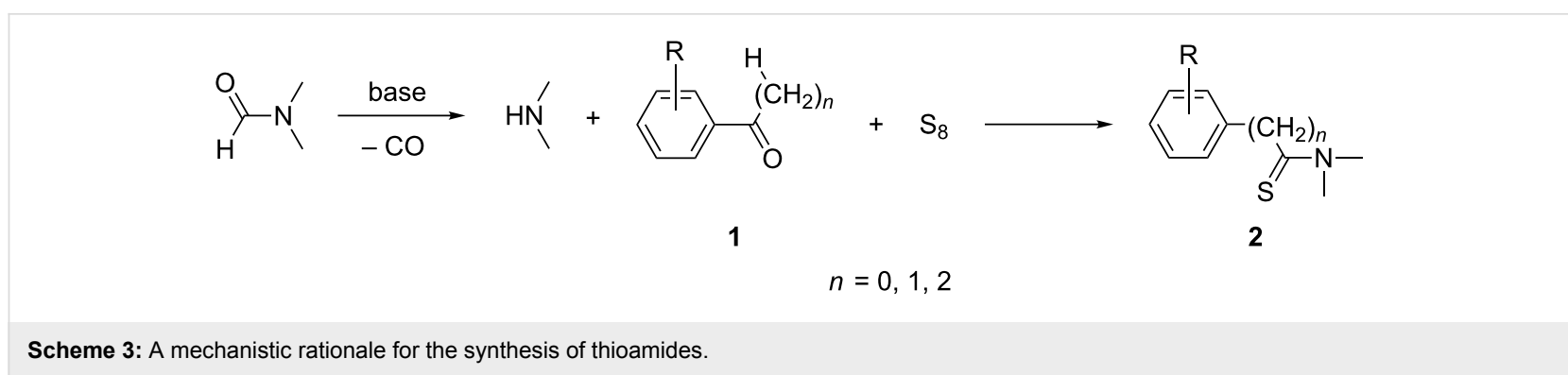

\section{Conclusion}

In summary, an improved synthetic procedure for the synthesis of thioamides has been established. This protocol is applicable to a wide range of aldehydes and ketones yielding the thioamides with excellent isolated yields. For this transformation, DMF works not only as the solvent but also as the source of dimethylamine. The present method is more practical compared to the traditional strategies and complements the classical methods for the rapid construction of thioamides.

\section{Supporting Information}

\section{Supporting Information File 1}

Full experimental details and copies of NMR spectra.

[http://www.beilstein-journals.org/bjoc/content/ supplementary/1860-5397-11-187-S1.pdf]

\section{Acknowledgements}

We thank the Excellent Young Scientist Fund of Guangdong Province Education Department (No.2013LYM_0059) for financial support.

\section{References}

1. Goldberg, J. M.; Speight, L. C.; Fegley, M. W.; Petersson, E. J. J. Am. Chem. Soc. 2012, 134, 6088-6091. doi:10.1021/ja3005094

2. Liu, C. T.; Maxwell, C. I.; Pipe, S. G.; Neverov, A. A.; Mosey, N. J.; Brown, R. S. J. Am. Chem. Soc. 2011, 133, 20068-20071. doi:10.1021/ja209605r

3. Batjargal, S.; Wang, Y. J.; Goldberg, J. M.; Wissner, R. F.; Petersson, E. J. J. Am. Chem. Soc. 2012, 134, 9172-9182. doi:10.1021/ja2113245

4. Murai, T.; Hori, F.; Maruyama, T. Org. Lett. 2011, 13, 1718-1721. doi:10.1021/ol200231z

5. Suzuki, Y.; Iwata, M.; Yazaki, R.; Kumagai, N.; Shibasaki, M. J. Org. Chem. 2012, 77, 4496-4500. doi:10.1021/jo300566p

6. Okano, A.; James, R. C.; Pierce, J. G.; Xie, J.; Boger, D. L. J. Am. Chem. Soc. 2012, 134, 8790-8793. doi:10.1021/ja302808p

7. Beattie, D. E.; Crossley, R.; Curran, A. C. W.; Dixon, G. T.; Hill, D. G.; Lawrence, A. E.; Shepherd, R. G. J. Med. Chem. 1977, 20, 714-718. doi:10.1021/jm00215a019

8. Zacharie, B.; Lagraoui, M.; Dimarco, M.; Penney, C. L.; Gagnon, L. J. Med. Chem. 1999, 42, 2046-2052. doi:10.1021/jm9900467
9. Goldberg, J. M.; Chen, X.; Meinhardt, N.; Greenbaum, D. C.; Petersson, E. J. J. Am. Chem. Soc. 2014, 136, 2086-2093. doi:10.1021/ja412297x

10. Goldberg, J. M.; Batjargal, S.; Chen, B. S.; Petersson, E. J. J. Am. Chem. Soc. 2013, 135, 18651-18658. doi:10.1021/ja409709x

11. Sherman, D. B.; Spatola, A. F.; Wire, W. S.; Burks, T. F.; Nguyen, T. M.-D.; Schiller, P. W. Biochem. Biophys. Res. Commun. 1989, 162, 1126-1132. doi:10.1016/0006-291X(89)90790-0

12. Albert, A.; Knecht, H.; Andersen, E.; Hungerford, V.; Schreier, M. H.; Papageorgiou, C. Bioorg. Med. Chem. 1998, 8, 2203-2208. doi:10.1016/S0960-894X(98)00365-5

13. Jeschke, P.; Harder, A.; Etzel, W.; Dau, W.; Thielking, G.; Bonse, G.; Linuma, K. Pest Manage. Sci. 2001, 57, 1000-1006. doi:10.1002/ps.382

14. Cynamon, M. H.; Gimi, R.; Gyenes, F.; Sharpe, C. A.; Bergmann, K. E.; Han, H. J.; Gregor, L. B.; Rapolu, R.; Luciano, G.; Welch, J. T. J. Med. Chem. 1995, 38, 3902-3907. doi:10.1021/jm00020a003

15. Guntreddi, T.; Vanjari, R.; Singh, K. N. Org. Lett. 2014, 16, 3624-3627. doi:10.1021/ol501482g

16. Bergman, J.; Pettersson, B.; Hasimbegovic, V.; Svensson, P. H. J. Org. Chem. 2011, 76, 1546-1553. doi:10.1021/jo101865y

17. Sun, Y.; Jiang, H.; Wu, W.; Zeng, W.; Li, J. Org. Biomol. Chem. 2014, 12, 700-707. doi:10.1039/С3ОВ42275E

18. Priebbenowa, D. L.; Bolm, C. Chem. Soc. Rev. 2013, 42, 7870-7880. doi:10.1039/c3cs60154d

19. Wang, X.; Ji, M.; Lim, S.; Jang, H.-Y. J. Org. Chem. 2014, 79, 7256-7260. doi:10.1021/jo501378v

20. Patra, M.; Hess, J.; Konatschnig, S.; Spingler, B.; Gasser, G. Organometallics 2013, 32, 6098-6105. doi:10.1021/om400715m

21. Nguyen, T. B.; Tran, M. Q.; Ermolenko, L.; Al-Mourabit, A. Org. Lett. 2014, 16, 310-313. doi:10.1021/ol403345e

22. Čechová, L.; Jansa, P.; Šála, M.; Dračínský, M.; Holý, A.; Janeba, Z. Tetrahedron 2011, 67, 866-871. doi:10.1016/j.tet.2010.12.040

23. Wang, J.; Hou, J.-T.; Wen, J.; Zhang, J.; Yu, X.-Q. Chem. Commun. 2011, 47, 3652-3654. doi:10.1039/c0cc05811d

24. Kumagai, T.; Anki, T.; Ebi, T.; Konishi, A.; Matsumoto, K.; Kurata, H.; Kubo, T.; Katsumoto, K.; Kitamura, C.; Kawase, T. Tetrahedron 2010, 66, 8968-8973. doi:10.1016/j.tet.2010.09.037

25. Wan, Y.; Alterman, M.; Larhed, M.; Hallberg, A. J. Org. Chem. 2002, 67, 6232-6235. doi:10.1021/j0025965a

26. Sharma, A.; Mehta, V. P.; Van der Eycken, E. Tetrahedron 2008, 64, 2605-2610. doi:10.1016/j.tet.2008.01.030

27. Amupitan, J. O. Synthesis 1983, 730-735. doi:10.1055/s-1983-30490

28. Nooshabadi, M.; Aghapoor, K.; Darabi, H. R.; Mojtahedi, M. M. Tetrahedron Lett. 1999, 40, 7549-7552. doi:10.1016/S0040-4039(99)01600-7 


\section{License and Terms}

This is an Open Access article under the terms of the Creative Commons Attribution License

(http://creativecommons.org/licenses/by/2.0), which permits unrestricted use, distribution, and reproduction in any medium, provided the original work is properly cited.

The license is subject to the Beilstein Journal of Organic Chemistry terms and conditions:

(http://www.beilstein-journals.org/bjoc)

The definitive version of this article is the electronic one which can be found at:

doi:10.3762/bjoc. 11.187 